\title{
Lipid infusion lowers sympathetic nervous activity and leads to increased $\beta$-cell responsiveness to glucose
}

\author{
Christophe Magnan, ${ }^{1}$ Stephan Collins, ${ }^{1}$ Marie-France Berthault, ${ }^{1}$ Nadim Kassis, ${ }^{1}$ \\ Mylène Vincent, ${ }^{1}$ Marc Gilbert, ${ }^{1}$ Luc Pénicaud, ${ }^{2}$ Alain Ktorza, ${ }^{1}$ \\ and Françoise Assimacopoulos-Jeannet ${ }^{3}$
}

${ }^{1}$ Laboratoire de Physiopathologie de la Nutrition, Centre National de la Recherche Scientifique ESA 7059, Université Paris 7, 75251 Paris Cedex 05, France

${ }^{2}$ Laboratoire de Neurobiologie, Plasticité Tissulaire et Métabolisme Energétique, Centre National de la Recherche Scientifique ESA 5018, Université Paul Sabatier, CHU Rangueil, 31000 Toulouse, France

${ }^{3}$ Département de Biochimie Médicale, Centre Médical Universitaire, CH1211 Geneva 4, Switzerland

Address correspondence to: Christophe Magnan, Laboratoire de Physiopathologie de la Nutrition, Centre National de la Recherche Scientifique ESA 7059, case 7126, Université Paris 7, 2 place Jussieu, 75251 Paris Cedex 05, France. Phone: 33-1-44-27-79-11; Fax: 33-1-44-27-78-36; E-mail: magnan@paris7.jussieu.fr

Received for publication April 30, 1998, and accepted in revised form November 30, 1998.

\begin{abstract}
We investigated the possible involvement of the autonomic nervous system in the effect of a long-term elevation of plasma free fatty acid (FFA) concentration on glucose-induced insulin secretion (GIIS) in rats. Rats were infused with an emulsion of triglycerides (Intralipid) for 48 hours (IL rats). This resulted in a twofold increase in plasma FFA concentration. At the end of infusion, GIIS as reflected in the insulinogenic index $(\Delta \mathrm{I} / \Delta \mathrm{G})$ was 2.5 -fold greater in IL rats compared with control saline-infused rats. The ratio of sympathetic to parasympathetic nervous activities was sharply decreased in IL rats relative to controls. GIIS was studied in the presence of increasing amounts of $\alpha$ - and $\beta$-adrenoreceptor agonists and antagonists. The lowest concentrations of the $\alpha 2 \mathrm{~A}$-adrenoreceptor agonist oxymetazoline, which were ineffective in control rats, reduced GIIS in IL rats. At the dose of $0.3 \mathrm{pmol} / \mathrm{kg}$, GIIS became similar in IL and control rats. The use of $\beta$-adrenoreceptor agonist (isoproterenol) or antagonist (propranolol) did not result in a significant alteration in GIIS in both groups. GIIS remained as high in IL vagotomized rats as in intact IL rats, indicating that changes in parasympathetic tone were of minor importance. Altogether, the data show that lipid infusion provokes $\beta$-cell hyperresponsiveness in vivo, at least in part through changes in $\alpha 2$-adrenergic innervation.
\end{abstract}

J. Clin. Invest. 103:413-419 (1999).

\section{Introduction}

Insulin resistance and hyperinsulinemia are considered as risk factors for coronary heart disease (reviewed in ref. 1). Growing evidence suggests that free fatty acids (FFA) play a key role in insulin action and insulin secretion and that they may be the common factor producing the alterations leading to peripheral insulin resistance and to $\beta$ cell dysfunction (reviewed in ref. 2). However, the precise role of high lipid levels on insulin secretion is far from being elucidated and remains largely controversial.

Based on in vitro studies, a long-term exposure (48 hours) to FFA results in a decreased insulin response to glucose in pancreatic $\beta$ cells (3-5). In contrast, a chronic increase in FFA levels exerts insulinotropic effects when insulin secretion is studied in vivo $(2,6,7)$.

The discrepancy between in vivo and in vitro studies concerning the effect of a long-term increase in FFA concentrations on $\beta$-cell function suggests the involvement of extrapancreatic factors. Among these factors, those of neural origin may be crucial. On one hand, the neuronal inputs of the pancreas include the parasympathetic and sympathetic system, whose activation results in the stimulation or the inhibition of insulin secretion, respectively (8). On the other hand, several experiments clearly showed that lipids may alter autonomic nervous system
(ANS) activity both in humans $(9-11)$ and in rats $(12,13)$. To study the possible interplay between a chronic elevation of FFA levels, insulin secretion, and ANS activity, normal rats were infused with a triglyceride emulsion over 48 hours, with subsequent measurements of $(a)$ the overall parasympathetic and sympathetic activities and (b) insulin secretion in response to glucose either in vitro (batch incubation islets) or in vivo after acute glucose loading. In addition, given that FFA increase the $\beta$-cell mass in vitro (14), the possible in vivo trophic effect of lipids on pancreatic islets was also investigated.

\section{Methods}

Animals. All rats were treated in accordance with the European Community guidelines, and the experimentation was approved by our local institution. Three-month-old female Wistar rats weighing 220-240 g were used. They were allowed free access to water and standard laboratory chow pellets (UAR 113; Usine d'Alimentation Rationnelle, Villemoisson sur Orge, France). A catheter was implanted under ketamine anesthesia $(125 \mathrm{mg} / \mathrm{kg}$, intraperitoneally; Imalgène, Mérieux, Lyon, France) in the right atrium via the jugular vein. A technique described previously $(15,16)$ for a 48 -h infusion in unrestrained rats was used for triglyceride or saline infusion. The infusion period started on day 2 after surgery. Rats were randomly divided into two groups. In the first group, rats were infused with a mixture of a 


\section{Table 1}

Time course of plasma TG, FFA, glycerol, $\beta$-hydroxybutyrate, and insulin concentrations during lipid infusion

\begin{tabular}{lccc}
\hline Time $(\mathrm{h})$ & 0 & 24 & 48 \\
TG $(\mathrm{mg} / \mathrm{l})$ & $0.92 \pm 0.20$ & $1.39 \pm 0.17^{\mathrm{A}}$ & $1.28 \pm 0.15$ \\
FFA $(\mathrm{mM})$ & $0.81 \pm 0.10$ & $1.96 \pm 0.20^{\mathrm{B}}$ & $2.02 \pm 0.20^{\mathrm{B}}$ \\
Glycerol $(\mu \mathrm{M})$ & $124 \pm 7$ & $556 \pm 53^{\mathrm{B}}$ & $413 \pm 49^{\mathrm{B}}$ \\
$\beta$-hydroxybutyrate $(\mu \mathrm{M})$ & $40 \pm 7$ & $423 \pm 55^{\mathrm{B}}$ & $472 \pm 60^{\mathrm{B}}$ \\
Insulin $(\mathrm{pM})$ & $190 \pm 18$ & $167 \pm 28$ & $178 \pm 6$
\end{tabular}

Values are means \pm SEM of lipid-infused rats. ${ }^{A} P<0.05 ;{ }^{B} P<0.001$ significantly different from time 0 . TG, triglycerides; FFA, free fatty acids.

$20 \%$ triglyceride emulsion (Intralipid KabiVitrum 2,000 kcal/1 and heparin $20 \mathrm{U} / \mathrm{ml}$; Intralipid KabiVitrum, Stockholm, Sweden) at a rate of $25 \mathrm{ml} / \mathrm{min} / \mathrm{kg}$ (lipids-infused [IL] rats). Control rats ( $\mathrm{C}$ rats) were infused with saline.

Plasma substrate and hormone concentrations. Blood samples obtained from the tail vessels were used for measurements of both substrate (glucose, triglycerides, glycerol, FFA, $\beta$-hydroxybutyrate) and insulin concentrations. Throughout the infusion period, measurements were performed once daily in both groups. The total blood volume withdrawn during the 48-h infusion period was $\sim 2 \mathrm{ml}$.

In vivo glucose-induced insulin secretion studies. After $48 \mathrm{~h}$ of infusion, a single injection of glucose $(0.5 \mathrm{~g} / \mathrm{kg})$ was administered in unrestrained rats via the intracardiac catheter. Blood samples were collected sequentially before and 5, 10, 15, 20, and 30 min after the glucose injection. Plasma was obtained after centrifugation, and glucose concentration was immediately determined on a $10-\mu \mathrm{l}$ aliquot. The remaining plasma was stored at $-20^{\circ} \mathrm{C}$ until insulin assay.

To appreciate the potential role of the sympathetic activity in the control of insulin secretion after lipid infusion, glucoseinduced insulin secretion (GIIS) was also studied in the presence of $\alpha 2 \mathrm{~A}$-adrenoreceptor ligands. In a first set of experiments, the $\alpha 2 \mathrm{~A}$-adrenoreceptor oxymetazoline (Sigma Chemical Co., St. Louis, Missouri, USA) was injected intraperitoneally $5 \mathrm{~min}$ before glucose loading. The insulin response was tested in the presence of $0.1,0.3,100$, and $1,000 \mathrm{pmol}$ of oxymetazoline $/ \mathrm{kg}$ of body weight. Each concentration corresponded to a different group of rats.

In another set of experiments, GIIS was investigated in the presence of the $\alpha 2$-adrenoreceptor antagonist yohimbine (Sigma Chemical Co.), which was injected intraperitoneally 5 min before glucose loading at doses $0.1,1,5$, and $10 \mu \mathrm{mol} / \mathrm{kg}$ of body weight.

To evaluate the possible involvement of the $\beta$-adrenergic pathway, GIIS was also performed in the presence of increasing amounts of $\beta$-adrenoreceptor antagonist propranolol (Sigma Chemical Co.) or agonist isoproterenol (Sigma Chemical Co.). In both experiments, the doses used were $0.2,0.4$, and 4 $\mu \mathrm{mol} / \mathrm{kg}$ of body weight. Each dose and each $\beta$-adrenoreceptor ligand corresponded to a different group of rats.

Finally, to appreciate the possible role of changes in parasympathetic tone, insulin secretion was also measured in vagotomized IL and control rats. Bilateral subdiaphragmatic vagotomy was performed under ketamine anesthesia, as described previously (17), just before catheter implantation. On day 2 after surgery, the infusions started under the same conditions as used for intact rats.

In vitro GIIS studies. At the end of both saline and lipid infusions, pancreases were removed and islets were isolated by collagenase (Collagenase; Boehringer Mannheim Biochemica, Mannheim, Germany). Insulin secretion studies were performed on islets freshly isolated from IL and control rats. In each experiment, 10-20 islets from the pancreas of one rat were first incubated for $90 \mathrm{~min}$ (equilibration period) at $37^{\circ} \mathrm{C}$ in $1 \mathrm{ml}$ of KrebsRinger bicarbonate buffer containing $5.5 \mathrm{mmol} / \mathrm{l}$ glucose and $0.5 \%$ BSA. The stimulatory effect of $5.5,11$, and $16.6 \mathrm{mmol} / \mathrm{l}$ glucose was then investigated for $60 \mathrm{~min}$. Measurement of islet DNA was performed by a fluorometric method with bisbenzimidazole as fluorochrome (18) after sonication of $\sim 20$ islets (2 $\times 15 \mathrm{~s})$ in $0.7 \mathrm{ml}$ of phosphate buffer. Another group of 10 islets was sonicated $(2 \times 10 \mathrm{~s})$ in $1.0 \mathrm{ml}$ of acid/alcohol for measurement of islet insulin content.

Morphometric investigations. Splenic parts of the pancreas of each rat were fixed in aqueous Bouin's solution at the end of the infusion period and embedded in paraffin. Each pancreatic block was serially sectioned $(7 \mu \mathrm{m})$ throughout its length to avoid any bias due to changes in islet distribution and cell composition, and mounted on slides. Adjacent sections at a fixed interval through the block (every 35 th section) were immunostained for insulin using a peroxidase indirect labeling technique. Briefly, the sections were incubated for $1 \mathrm{~h}$ with guinea pig anti-insulin serum (final dilution 1:1,000; ICN Biochemicals, Aurora, Ohio, USA). Thereafter, sections were incubated for $45 \mathrm{~min}$ with peroxidase-conjugated rabbit anti-guinea pig IgG (final dilution 1:20; DAKO Corp., Carpinteria, California, USA). The activity of antibody-peroxidase complex was revealed with 3,3'-diaminobenzidine-tetra-hydrochloride using a peroxidase substrate kit (Biosys-Vector, Compiègne, France). After staining, sections were mounted in Eukitt (Labonord, Freiburg, Germany).

Total insulin-positive cell-mass quantification. Insulin-positive cell ( $\beta$ cells) areas were measured using an Olympus BH2 microscope (Olympus Optical Co., Tokyo, Japan) connected via a color video camera to a Compaq PC computer (Compaq Computer Corp., Issy-lès-Moulineaux, France) and Imagenia 2000 software (Biocom, Les Ulis, France). The area of insulin-positive cells, as well as that of total pancreatic sections, was evaluated in each stained section. $\beta$-cell areas were determined by calculating the ratio between the area occupied by immunoreactive cells and that occupied by total pancreatic area on 10 sections for each

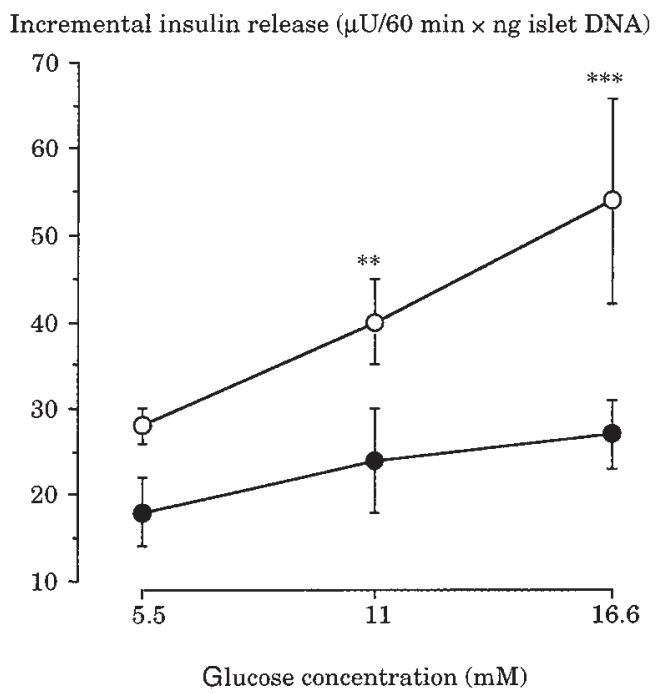

\section{Figure 1}

Effects of increasing concentrations of glucose on insulin release by freshly isolated islets of control (open circles) and lipids-infused (filled circles) rats. Values are means \pm SEM of five cases for both groups. ${ }^{* *} P<0.01$, *** $P<0.001$, significantly different from $5.5 \mathrm{mM}$ glucose. 
pancreas. All insulin-positive cells were examined in each of the 10 sections studied. The $\beta$-cell mass was derived by multiplying the $\beta$-cell relative volume by the total pancreatic weight.

Individual $\beta$-cell area. $\beta$-cell size was measured on insulinstained sections by evaluating the mean cross-sectional area of individual $\beta$ cells. The $\beta$-cell nuclei on a random section were counted, and area of $\beta$-cell tissue in that section measured by planimetry as described above. The $\beta$-cell area was divided by the number of nuclei to calculate the area of individual $\beta$ cells. Using this technique, it must be recognized that the actual number of $\beta$ cells is probably higher than the number counted, because not all $\beta$ cells are sectioned across their nuclei and, therefore, the size of $\beta$ cells is overestimated.

Sympathetic and parasympathetic firing-rate recordings. Firing-rate activities were recorded at the end of the infusion at the level of the superior cervical ganglion (sympathetic activity), and the thoracic branch of the vagus nerve, along the carotid artery (parasympathetic activity) as described previously (17). Different rats were used for recording either activity.

Sympathetic activity recording was done as follows: rats were anesthetized intraperitoneally with $50 \mathrm{mg} / \mathrm{kg}$ of body weight of pentobarbital sodique (Sanofi, Libourne, France). The sympathetic nerve, which is close to the carotid artery, was dissected free of underlying tissues on a distance of approximately $1 \mathrm{~cm}$ until the superior cervical ganglion. The nerve was then covered with paraffin oil to prevent dehydration and carefully placed on a pair of recording silver wire electrodes (0.6- $\mathrm{mm}$ diameter). Electrodes were connected to a high-impedance probe, amplified by $10^{4}$ with an alternative-current amplifier (time constant $0.2 \mathrm{~s})$ and filtered at low- and high-frequency cutoffs (1-80 $\mathrm{kHz}$ ). The filtered, amplified signal was routed to an oscilloscope and a pen recorder and stored on a magnetic tape for further analysis.

A very similar experimental design was used for parasympathetic activity recording. After exposure of the carotid artery, the thoracic branch of the vagus nerve was carefully separated from surrounding tissues. The follow-up of the procedure was identical to that described for sympathetic nerve activity recording.

Analytical methods. Plasma glucose level was determined with the glucose oxidase technique using a glucose analyzer (Beckmann, Brea, California, USA). Plasma immunoreactive insulin (plasma IRI) was measured by RIA (DiaSorin, Antony, France). The lower limit of the assay was $15 \mathrm{pmol} / 1$, for use with a coefficient of variation within and between assays of $6 \%$.

Glucose tolerance was measured using the $\Delta \mathrm{G}$, which represents the increase of glycemia over a period of $30 \mathrm{~min}$ after glucose load. Insulin secretion was calculated as the incremental plasma insulin values integrated over a 30 -min period after the injection of glucose $(\Delta \mathrm{I})$.

Plasma FFA, glycerol, triglyceride, and $\beta$-hydroxybutyrate concentrations were determined by enzymatic assay kits (Boehringer Mannheim Biochemica, for glycerol, triglycerides, and $\beta$-hydroxybutyrate; and Wako Chemical, Marburg, Germany, for FFA).

Statistics. Results are given as means \pm SEM. Statistical analyses were performed using ANOVA.

\section{Results}

Plasma substrate and insulin concentrations. During the first 24 hours of lipid infusion, plasma FFA and glycerol concentrations increased significantly by approximately twofold and fivefold, respectively (Table 1), and then remained stable for the rest of the study. Plasma triglyceride levels were moderately increased during the first 24 hours and were back to the basal value at 48 hours. Plasma $\beta$-hydroxybutyrate level increased significantly
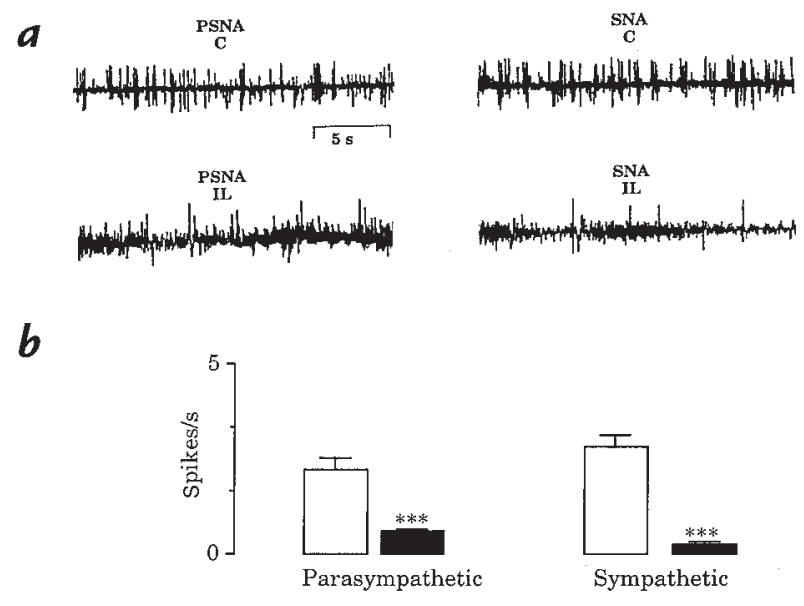

$c$

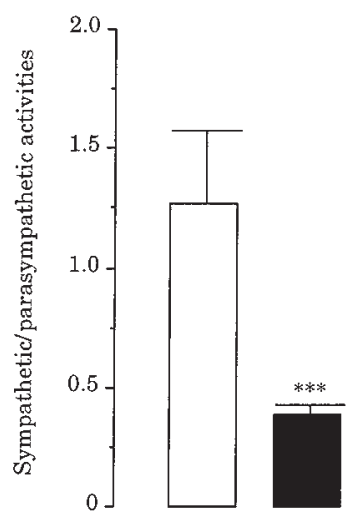

Figure 2

(a) Fragments of illustrative recordings of parasympathetic (PSNA) and sympathetic (SNA) nerve activity from control (C) and lipids-infused (IL) rats. (b) Parasympathetic and sympathetic activities in control (open bars) and IL (filled bars) rats. Recorded from vagus nerve and superior cervical ganglion, respectively. Values are means \pm SEM of five cases for both groups. ${ }^{* *} P<0.001$, significantly different from controls. (c) Ratio of sympathetic to parasympathetic nerve activities.

during the first 24 hours and remained unchanged throughout the 24- to 48-hour time interval. Plasma glucose concentration did not change significantly throughout the infusion period (48-hour infusion period: control rats, $5.2 \pm 0.4 \mathrm{mM}$; IL rats, $4.8 \pm 0.3 \mathrm{mM}$ ). In IL rats, there were no significant changes in plasma IRI concentration during the infusion period.

Effect of lipid infusion on in vitro GIIS. GIIS was significantly lowered in islets of IL rats compared with islets of controls (Fig. 1). Neither islet insulin nor DNA content was modified in IL rats relative to controls (ng of insulin/islet: $\mathrm{C}$ rats, $8.3 \pm 0.7[n=6]$; IL rats, $8.8 \pm 0.9[\mathrm{n}$ $=5]$; ng of DNA/islet: $\mathrm{C}$ rats, $25.0 \pm 3.2[n=6]$; IL rats, $26.3 \pm 2.5[n=5]$.

Sympathetic and parasympathetic nerve activities. At the end of lipid infusion, both sympathetic and parasympathetic nerve activities were significantly decreased relative to control rats (Fig. 2b). However, the decrease in sympathetic nerve activity was much greater than that of parasympathetic nerve activity. This is reflected in the ratio of sympathetic to parasympathetic nervous activity (Fig. 2c). 


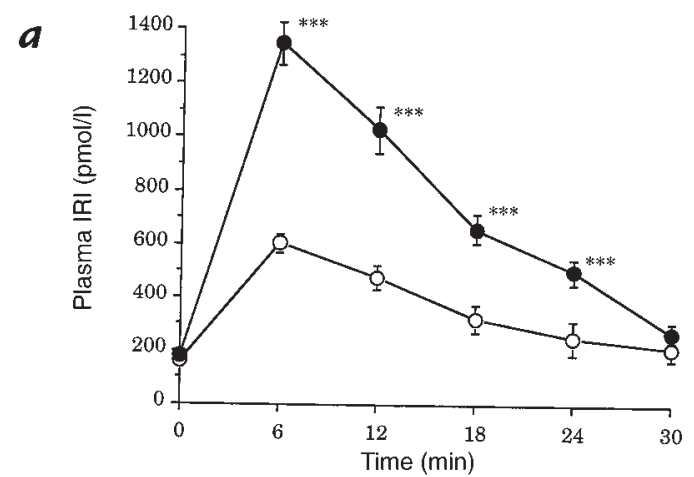

$b$

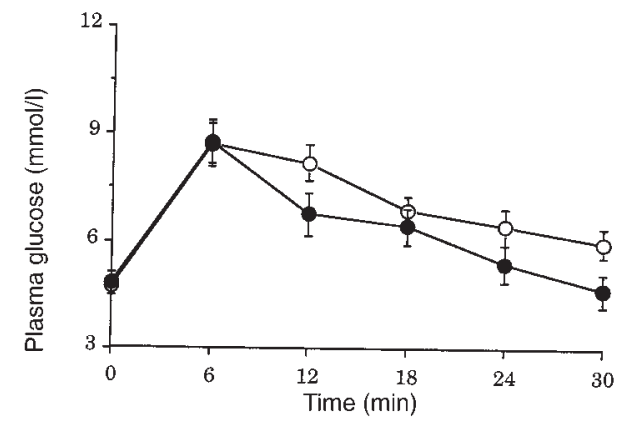

$c$

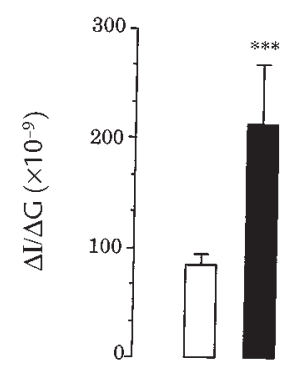

Figure 3

Time course of plasma insulin $(\boldsymbol{a})$ and glucose $(\boldsymbol{b})$ concentrations in response to glucose loading in control (open circles) and IL (filled circles) rats. Values are means \pm SEM of 10 cases for both groups. (c) Insulinogenic index $(\Delta \mathrm{l} / \Delta \mathrm{G})$ in control (open bar) and IL (filled bar) rats. ${ }^{*}{ }^{*} P<$ 0.001 , significantly different from control rats.

Effect of lipid infusion on in vivo GIIS. The in vivo time course of plasma glucose and insulin concentrations before and after a glucose load are depicted in Fig. $3 a$. At time 0 , plasma insulin concentration was similar in both groups. After glucose injection, insulin level was significantly higher at each time point in IL rats compared with controls (Fig. $3 a$ ). Changes in glucose concentration were quite similar in both groups (Fig. $3 b$ ). Consequently, the insulinogenic index $(\Delta \mathrm{I} / \Delta \mathrm{G})$ was about 2.5 -fold greater in IL rats than in controls (Fig. $3 c$ ).

In vivo GIIS in control and IL rats treated either with $\alpha$-or $\beta$ adrenoreceptor ligands. In IL rats, in the presence of an increasing amount of oxymetazoline $(0.1,0.3,100$, and 1,000 $\mathrm{pmol} / \mathrm{kg}), \Delta \mathrm{I} / \Delta \mathrm{G}$ was significantly reduced by $33 \%, 57 \%$, $75 \%$, and $90 \%$, respectively (Fig. $4 a$ ). In contrast, in control rats, $\Delta \mathrm{I} / \Delta \mathrm{G}$ remained unchanged when animals were given 0.1 and $0.3 \mathrm{pmol} / \mathrm{kg}$ of oxymetazoline, whereas it was reduced by approximately $45 \%$ and $83 \%(P<0.01)$ in the presence of 100 and 1,000 pmol/kg, respectively (Fig. 4a).
In the presence of 0.1 and $1 \mu \mathrm{mol} / \mathrm{kg}$ of yohimbine, there were no changes in $\Delta \mathrm{I} / \Delta \mathrm{G}$ in both control and IL groups compared with their respective basal values (Fig. $4 b)$. In the presence of $5 \mu \mathrm{mol} / \mathrm{kg}$, there was an increase in $\Delta \mathrm{I} / \Delta \mathrm{G}$ in control rats, whereas the parameters remained unchanged in IL rats (Fig. 4b). When experiments were performed at the pharmacological dose of $10 \mu \mathrm{mol} / \mathrm{kg}$, there was an increase in $\Delta \mathrm{I} / \Delta \mathrm{G}$ in both groups, but this increase was much more marked in control rats (163\%) than in IL rats $(72 \%)$. Concerning experiments with $\beta$ adrenoreceptor ligands, regardless of dose used $(0.2,0.4$, or $4 \mu \mathrm{mol} / \mathrm{kg}$ ), neither isoproterenol (Fig. $5 \mathrm{a}$ ) nor propranolol (Fig. $5 b$ ) modified GIIS in both control and IL rats.

In vivo GIIS after suppression of vagal activity. In control rats, subdiaphragmatic vagotomy resulted in a significant decrease in $\Delta \mathrm{I} / \Delta \mathrm{G}$ compared with intact control rats (Fig. 6). In contrast, $\Delta \mathrm{I} / \Delta \mathrm{G}$ remained similar in IL vagotomized rats compared with intact IL rats (Fig. 6).

Effect of lipid infusion on insulin-positive cells. To further evaluate the effects of lipid infusion on the relative number of insulin-positive cells and on $\beta$-cell area, morphometric quantifications were performed in sections of pancreas of control and IL rats. In IL rats, there was an increase in the ratio of insulin-positive cell area to total pancreatic area when compared with control rats ( $\mathrm{C}$ rats, $0.53 \pm 0.04[n=5]$; IL rats, $0.81 \pm 0.08[n=6] ; P<0.01)$. However, when the weight of the pancreas was taken into account, the relative volume of the insulin-positive cells did not differ significantly in both group. Indeed, pancreatic weight was significantly lower in IL rats $(582 \pm 57$ $\mathrm{mg} ; n=5)$ than in control rats $(980 \pm 108 \mathrm{mg} ; P<0.01, n$ $=5$ ). There was no difference in individual $\beta$-cell size between the two groups.

\section{Discussion}

The data obtained in the present study provide evidence of the involvement of the sympathetic nervous system in the insulinotropic effect of elevated FFA plasma concentrations. Neural factors were likely candidates to explain the in vivo/in vitro discrepancies because of their importance in the control of insulin secretion (8) and the ability of circulating substrates, including FFA, to alter ANS activity $(12,13,17)$. Moreover, the influence of other possible stimulating factors of insulin secretion, such as gut hormones, was excluded because lipids were intravenously infused.

At first, we found that glucose was unable to substantially stimulate in vitro insulin secretion of isolated islets previously exposed to elevated FFA for 48 hours in vivo. This is in keeping with previous studies (19-21) showing a decrease in glucose-induced insulin release in vitro after long-term exposure to high FFA concentration. This situation may be related to a decrease in glucose oxidation and insulin secretion through an alteration of gene expression or enzyme activity such as pyruvate dehydrogenase (20) or carnitine palmitoyltransferase I (21). Recent data also reported that GLUT2 and glucokinase mRNA expression are decreased in isolated pancreatic islets exposed to palmitate for 48 hours (22). A shortterm exposure of pancreatic $\beta$ cells $(3,23-25)$ or clonal human insulinoma tumoral cell line (26) to elevated FFA concentrations in the presence of stimulating glucose 
leads to an increase in insulin secretion. Therefore, the effect of high levels of FFA on in vitro insulin secretion seems to be time-dependent. This is fairly illustrated by the study of Sako and Grill (3), who showed that a threeto six-hour lipid infusion in normal rats leads to an increase in GIIS in vitro, whereas a 48-hour lipid infusion results in a decrease in GIIS.

The poor insulin response to glucose that we observe in vitro after FFA infusion strikingly contrasts with the high $\beta$-cell responsiveness to glucose when it is assessed in vivo. This is in agreement with the study of Akiyama et al. (7), who observed that after a very long period (27 days) of fat infusion, normal rats still display a greater insulin response to glucose. Moreover, some clinical observations are fitted to our data. Basal hyperinsulinemia, which is a characteristic of obesity in a prenon-insulin-dependent diabetes mellitus (NIDDM) state, is known to be due, at least in part, to an increased pancreatic insulin secretion (2). Furthermore, in healthy subjects, a prolonged (48 hours) elevation of plasma FFA concentration during a hyperglycemic clamp results in a greater hyperinsulinemia compared with controls (6).

The data clearly show that both sympathetic and parasympathetic activities were markedly altered by FFA infusions, as indicated by the firing rates from the superior cervical ganglion and from the thoracic vagus nerve. Despite conflicting results, there are reports showing that elevated plasma FFA concentrations may modify the ANS activity, especially sympathetic nervous activity (9-11). In healthy subjects, a depression in both activities is associated with an increasing percentage of body fat, which indirectly reflects the hyperlipidemia (9). However, earlier reports instead indicate that obesity brings about sustained sympathetic activation $(10,11)$. These contradictory results can be explained by the fact that obese subjects are both hyperlipidemic and hyperinsulinemic, and a high insulin level is known to activate the sympathetic nervous activity $(10,27)$. To explain the decrease in ANS activity (parasympathetic and sympathetic) in IL rats, one should expect that FFA send a signal(s) to central nervous system sites involved in the control of the ANS output. Earlier reports are indicative of such a possibility because triglyceride infusion has significant doserelated central nervous toxicity in dogs (28).

In IL rats, the decrease in sympathetic activity induced by FFA is fitted to the elevated GIIS. In contrast, the decline in parasympathetic activity would theoretically not favor high insulin secretion. However, looking at the ratio of their respective activity, it is clear that the decrease in sympathetic activity is much more marked than the parasympathetic one. It was therefore reasonable to hypothesize that the $\beta$-cell hypersensitivity to glucose in vivo was mainly due to the decrease in the sympathetic activity. Accordingly, the crucial role of the decrease in sympathetic activity compared with the parasympathetic one after chronic elevation of plasma FFA concentration is stressed by the absence of effect of vagotomy on insulin secretion in IL rats compared with controls.

To evaluate the importance of changes in $\alpha 2 \mathrm{~A}$-adrenergic innervation, we used a very specific $\alpha 2 \mathrm{~A}$ adrenoreceptor agonist, oxymetazoline, because it is well established that the norepinephrine (NE) released
$\Delta \mathrm{I} / \Delta \mathrm{G}\left(\times 10^{-9}\right)$

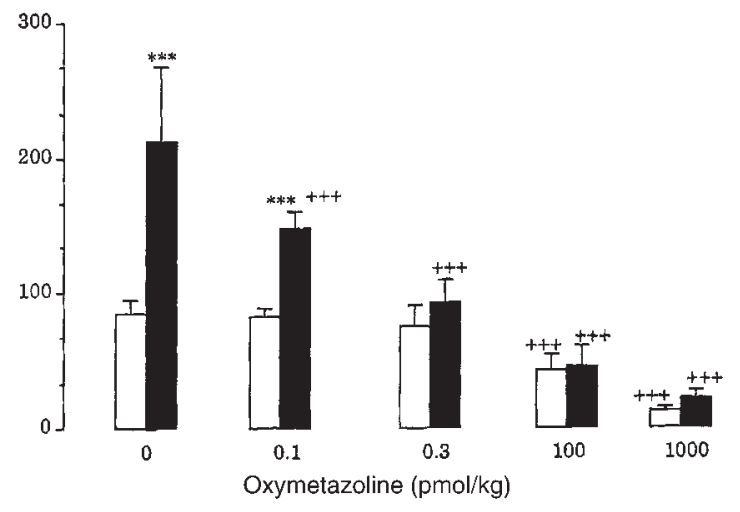

$\Delta \mathrm{V} / \Delta \mathrm{G}\left(\times 10^{-9}\right)$

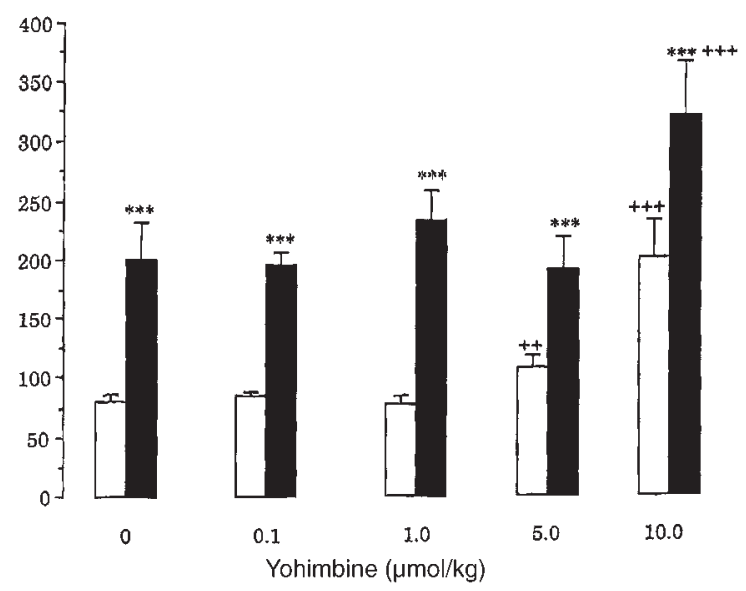

Figure 4

Insulinogenic index $(\Delta \mathrm{l} / \Delta \mathrm{G})$ in response to glucose loading in presence of increasing amounts of either oxymetazoline or yohimbine in control (open bars) and IL (filled bars) rats. Values are means \pm SEM of six cases for each dose. ${ }^{* *} P<0.001$, significantly different from control rats. ${ }^{++} P<$ $0.05,{ }^{++} P<0.001$, significantly different from basal value (without oxymetazoline or yohimbine).

by the postsynaptic nerve exerts its inhibitory effect on insulin secretion primarily through this type of receptor (29). Using increasing amount of oxymetazoline, $\beta$ cell responsiveness to glucose was progressively blunted in IL rats, whereas controls were not sensitive to low concentrations of oxymetazoline. At the dose of 0.3 $\mathrm{pmol} / \mathrm{kg}$, GIIS became similar in IL and control rats. This is a first clear indication of the importance of the low sympathetic activity in the high insulin response in vivo in IL rats.

The data obtained from the experiments using yohimbine reinforce this conclusion. Indeed at the dose of 5 $\mu \mathrm{mol} / \mathrm{kg}$, the $\alpha 2$ antagonist significantly increased GIIS in control rats, whereas it was ineffective in IL rats, thus demonstrating that lowering $\alpha 2$-adrenergic influence did not result in an increase of insulin secretion in IL rats. Note that at the pharmacological dose of 10 $\mu \mathrm{mol} / \mathrm{kg}$, yohimbine increased GIIS in IL rats but to a much lesser extent than in controls. This suggests that the maximal pancreatic $\beta$-cell response to glucose was not reached even in IL rats. 

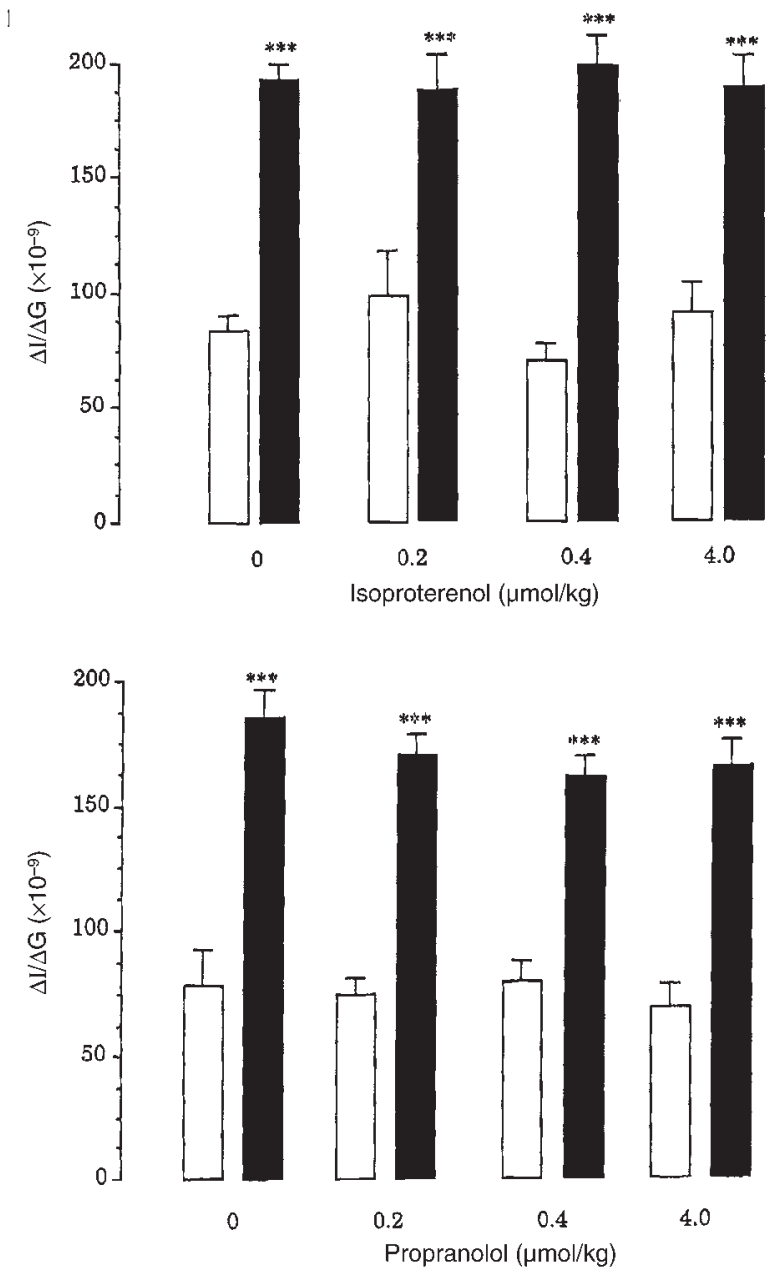

Figure 5

Insulinogenic index $(\Delta \mathrm{l} / \Delta \mathrm{G})$ in response to glucose loading in the presence of increasing amounts of isoproterenol $(\boldsymbol{a})$ or propranolol $(\boldsymbol{b})$ in control (open bars) and IL (filled bars). Values are means \pm SEM of six cases for each dose. ${ }^{* *} P<0.001$, significantly different from controls.

Using $\beta$-adrenoreceptor agonist and antagonist, we did not observe any modification in regard to GIIS in both groups of rats. This result suggests that the insulin stimulating $\beta$-adrenergic pathway is not involved in the $\beta$-cell hyperresponsiveness to glucose in our model. This is in keeping with the 100 -fold lower number of $\beta$-adrenoreceptors compared with $\alpha$-adrenoreceptors on $\beta$-cell surface $(30,31)$ and is in agreement with the fact that $\alpha$ adrenergic control of insulin secretion predominates over the $\beta$-adrenergic one in vivo (8).

Islet hypersensitivity to oxymetazoline in IL rats suggests that elevated FFA level may increase the number of binding sites and/or the specific ligand-receptor affinity. Such mechanisms need to be further elucidated, and, to our knowledge, there is no study showing a direct effect of FFA on $\alpha$-adrenergic responsiveness. Alternatively, but not contradictorily, this situation could result from the low sympathetic tone and the low NE release. This inverse relationship has been reported in elderly subjects, because a decrease in sympathetic nervous activity induced by an antagonist of the NE (guanadrel) upregulates the $\alpha 2 \mathrm{~A}$-adrenoreceptor expression (32). Inversely, when the sympathetic nervous activity is increased in elderly humans, the arterial $\alpha$-adrenergic responsiveness is decreased (33). To reinforce the concept of the interrelationship between the ANS activity and the expression of adrenergic receptor, it was shown, in dogs, that intrapericardial denervation (parasympathetic and sympathetic nerves) results in a $190 \%$ increase in $\beta$-adrenergic receptor density (34). Finally, Zoukos et al. (35) showed that a reduction in central sympathetic outflow by clonidine results in an upregulation of $\beta$ adrenoreceptor on circulating mononuclear cells in normal subjects (35). Taken together, these data emphasize that a reduction in sympathetic activity might have a functional impact in a wide range of tissues in modifying the adrenoreceptor expression or binding.

We also addressed the question of whether an increase in $\beta$-cell mass could have occurred in response to increase in plasma FFA concentration, and consequently could have enhanced in the $\beta$-cell response to glucose. Morphometric investigations performed in IL rats seemed to indicate an increase in $\beta$-cell area. However, the total pancreas weight was sharply decreased in IL rats compared with controls rats. This could be attributed to the decreased parasympathetic activity, because pancreas weight seems to be partly dependent on vagal activity (36). As a consequence, the $\beta$-cell mass expressed per milligram of pancreas did not differ significantly in both groups. In support of this, the islet DNA content and $\beta$-cell individual size remained unchanged. However, a previous work (14) showed that hyperplasia can be obtained in normal rat islets cultured for seven days with 2 -mM concentrations of FFA and that hypersecretion of insulin by islets of obese Zucker fatty rats could be related to pancreatic $\beta$-cell hyperplasia. This discrepancy with our data can be partly explained by the experimental approaches, in vitro versus in vivo, and by the duration of FFA exposure.

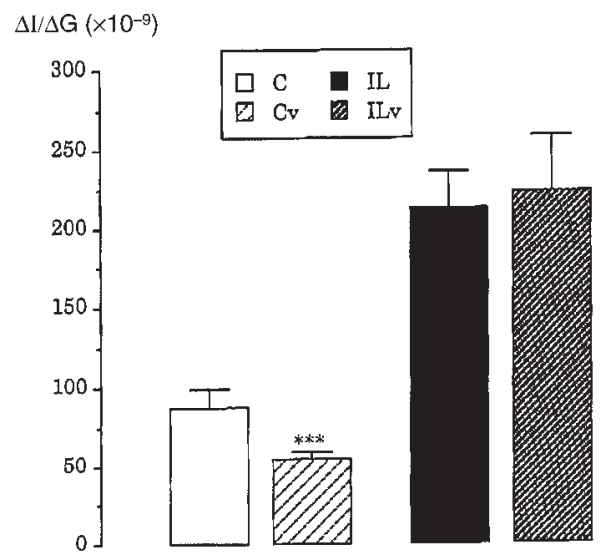

Figure 6

Insulinogenic index $(\Delta \mathrm{l} / \Delta \mathrm{G})$ in response to glucose loading in control and lipids-infused rats under subdiaphragmatic vagotomy. Values are means \pm SEM of six cases for all groups. ${ }^{* *} P<0.001$, significantly different from intact rats. $C$, control rats; $C V$, control vagotomized rats; IL, lipidsinfused rats; $I L v$, lipids-infused vagotomized rats. 
At last, elevated insulin levels in vivo could be also partly ascribed to diminished hepatic clearance of insulin. Indeed, Svedberg et al. (37) reported that FFA reduce the hepatic insulin extraction in perfused rat liver in situ. In the present study, such a mechanism is unlikely because there was no increase in basal plasma insulin concentration.

The $\beta$-cell hyperresponse to glucose seen in IL rats is far from being an indication of improved $\beta$-cell function but could rather be the initial step in a cascade of events leading to the deterioration of $\beta$-cell function, as reported by others. Hansen and Bodkin (38) observed that during development of NIDDM in the rhesus monkey, the insulin response to glucose was first increased. In the $\mathrm{db} / \mathrm{db}$ mouse, hyperinsulinemia and increased glucose-induced insulin secretion precede detectable impairment of glucose homeostasis. Diabetes develops concomitantly with the decline of insulin release and $\beta$-cell responsiveness (39). It may be hypothesized that in obese NIDDM subjects, chronic elevation of plasma FFA concentration contributes to the progressive deterioration of insulin secretion according to the same sequence of events. A recent study by Bollheimer et al. (25) agrees with this hypothesis. The authors observed that chronic exposure of pancreatic $\beta$ cells to FFA resulted in increasing basal insulin release and a decrease in proinsulin stores, which could lead to $\beta$-cell exhaustion and pancreatic dysfunction.

In conclusion, high FFA levels induced by a 48-hour lipid infusion results in a decrease in sympathetic nervous activity, which is related to the in vivo $\beta$-cell hyperresponsiveness to glucose loading. Further studies are required to evaluate the precise role of elevated plasma FFA concentration and the specific targets of individual FFA in the central nervous system and/or ANS output.

\section{Acknowledgments}

This study was supported in part by grant 32-4597.95 from the Fonds National Suisse de la Recherche Scientifique.

1. Reaven, G., Lithell, H., and Landsberg, L. 1996. Hypertension and associated metabolic abnormalities - the role of insulin resistance and the sympathoadrenal system. N. Engl. J. Med. 334:374-381.

2. Unger, R. 1995. Lipotoxicity in the pathogenesis of obesity-dependent NIDDM. Genetic and clinical implications. Diabetes. 44:863-870.

3. Sako, Y., and Grill, V.A. 1990. 48-hour lipid infusion in the rat timedependently inhibits glucose-induced insulin secretion and B cell oxidation through a process likely coupled to fatty acid oxidation. Endocrinology. 127:1580-1589.

4. Liang, X., Buettger, C., Berner, D., and Matchinsky, F. 1997. Chronic effect of fatty acids on insulin release is not through the alteration of glucose metabolism in a pancreatic beta-cell line (bHC9). Diabetologia. 40:1018-1027.

5. Man, Z. et al. 1997. Impaired $\beta$-cell function and deposition of fat droplets in the pancreas as a consequence of hypertriglyceridemia in OLETF rat, a model of spontaneous NIDDM. Diabetes. 46:1718-1724.

6. Boden, G., Chen, X., Rosner, J., and Barton, M. 1995. Effects of 48h fat infusion on insulin secretion and glucose utilization. Diabetes. 44:1239-1242.

7. Akiyama, T., Tachibana, I., Shirohara, H., Watanabe, N., and Otsuki, M. 1996. High-fat hypercaloric diet induces obesity, glucose intolerance and hyperlipidemia in normal adult male Wistar rat. Diabetes Res. Clin. Pract. 31:27-35

8. Ahren, B., Taborsky, G., and Porte, D. 1986. Neuropeptidergic versus cholinergic and adrenergic regulation of islet hormone secretion. Dia betologia. 29:827-836.

9. Peterson, H., et al. 1988. Body fat and the activity of the autonomic nervous system. N. Engl. J. Med. 318:1077-1083.

10. Troisi, R., et al. 1991. Relation of obesity and diet to sympathetic nervous system activity. Hypertension. 5:669-677.

11. Scherrer, U., Owlya, R., and Lepori, M. 1996. Body fat and sympathetic nerve activity. Cardiovasc. Drugs Ther. 10:215-222.
12. Levin, B., Triscari, J., and Sullivan, A. 1983. Relationship between sympathetic activity and diet-induced obesity in two rat strains. Am. J. Physiol. 245:R367-R371.

13. Young, J., and Walgren, M. 1994. Differential effects of dietary fats on sympathetic nervous system activity in the rat. Metabolism. 43:51-60.

14. Milburn, J., et al. 1995. Pancreatic $\beta$-cells in obesity: evidence for induction of functional, morphologic, and metabolic abnormalities by increased long chain fatty acids. J. Biol. Chem. 270:1295-1299.

15. Ktorza, A., Girard, J., Kinebanyan, M.F., and Picon, L. 1981. Hyperglycaemia induced by glucose infusion in the unrestrained pregnant rat during the last three days of gestation: metabolic and hormonal changes in the mother and fetuses. Diabetologia. 21:569-574.

16. Laury, M., et al. 1989. In vivo insulin secretion and action in hyperglycemic rat. Am. J. Physiol. 257:E180-E184.

17. Nguyen, J., et al. 1994. Involvement of the autonomic nervous system in the in vivo memory to glucose of pancreatic $\beta$ cell in rats. J. Clin. Invest. 94:1456-1462.

18. Labarca, C., and Paigen, K. 1980. A rapid and sensitive DNA assay procedure. Anal. Biochem. 102:344-352.

19. Zhou, Y., and Grill, V. 1994. Long term exposure of rat pancreatic islets to fatty acids inhibits glucose-induced insulin secretion and biosynthesis through a glucose fatty acid cycle. J. Clin. Invest. 93:870-876.

20. Zhou, Y., and Grill, V. 1995. Palmitate-induced $\beta$-cell insensitivity to glucose is coupled to decreased pyruvate dehydrogenase activity and enhanced kinase activity in rat pancreatic islets. Diabetes. 44:394-399.

21. Assimacopoulos-Jeannet, F., et al. 1997. Fatty acids rapidly induce the carnitine palmitoyltransferase I gene in the pancreatic $\beta$-cell line INS-1. $J$. Biol. Chem. 272:1659-1664.

22. Gremlich, S., Bonny, C., Waeber, G., and Thorens, B. 1997. Fatty acids decrease IDX-1 expression in rat pancreatic islets and reduce GLUT2, glucokinase, insulin, and somatostatin levels. J. Biol. Chem. 272:30261-30269.

23. Warnotte, C., Gilon, P., Nenquin, M., and Henquin, J. 1994. Mechanisms of the stimulation of insulin release by saturated fatty acids. Diabetes. 43:703-711.

24. Hosokawa, H., Corkey, B., and Leahy, J. 1997. Beta-cell hypersensitivity to glucose following 24-h exposure of rat islets to fatty acids. Diabetologia. 40:392-397.

25. Bollheimer, L., Skelly, R., Chester, M., McGarry, J., and Rhodes, C. 1998. Chronic exposure to free fatty acid reduces pancreatic $\beta$ cell insulin content by increasing basal insulin secretion that is not compensated for by a corresponding increase in proinsulin biosynthesis translation. J. Clin. Invest. 101:1094-1101.

26. Prentki, M., et al. 1992. Malonyl-CoA and long chain acyl-CoA esters as metabolic coupling factors in nutrient-induced insulin secretion. J. Biol. Chem. 267:5802-5810.

27. Vollenweider, P., et al. 1993. Differential effects of hyperinsulinemia and carbohydrate metabolism on sympathetic nerve activity and muscle blood flow in humans. J. Clin. Invest. 92:147-154.

28. Miles, J., et al. 1991. Metabolic and neurologic effects of an intravenous medium-chain triglyceride emulsion. J. Parenter. Enteral. Nutr. 15:37-41.

29. Angel, I., Niddam, R., and Langer, S. 1990. Involvement of alpha2adrenoreceptor subtypes in hyperglycemia. J. Pharmacol. Exp. Ther. 254:877-882.

30. Fyles, J., Cawthorne, M., and Howell, S. 1987. The determination of alpha-adrenergic receptor concentration on rat pancreatic islet cells. Biosci. Rep. 7:17-22.

31. Fyles, J., Cawthorne, M., and Howell, S. 1986. The characteristics of betaadrenergic binding sites on pancreatic islets of Langerhans. J. Endocrinol. 111:263-270.

32. Supiano, M., Hogykian, R., Stoltz, A., Orstan, N., and Halter, J. 1991. Regulation of venous $\alpha$-adrenergic responses in older humans. Am.J. Physiol. 260:E599-E607.

33. Hogikyan, R., and Supiano, M. 1995. Arterial $\alpha$-adrenergic responsiveness is decreased and SNS activity is increased in older humans. Am.J. Physiol. 266:E717-E724.

34. Valette, H., et al. 1995. Canine myocardial beta adrenergic, muscarinic receptor densities after denervation: a PET study. J. Nucl. Med. 36:140-146.

35. Zoukos, Y., et al. 1992. Up-regulation of beta-adrenoceptor on circulating mononuclear cells after reduction of central sympathetic outflow by clonidine in normal subjects. Acta Neurol. Scand. 2:165-170.

36. Kiba, T., Tanaka, K., Inoue, S., Endo, O., and Takamura, Y. 1991. Comparison of DNA contents of visceral organs in rats with ventromedial hypothalamic lesions and fed high fat diet. Neurosci. Lett. 126:127-130.

37. Svedberg, J., Strömblad, G., Wirth, A., Smith, U., and Björntorp, P. 1991. Fatty acids in the portal vein of the rat regulate hepatic insulin clearance. J. Clin. Invest. 88:2054-2058.

38. Hansen, B., and Bodkin, N. 1990. Beta cell hyperresponsiveness: earliest event in development of diabetes in monkeys. Am. J. Physiol. 259:R612-R617.

39. Shafrir, E. 1990. Diabetes in animals. In Diabetes mellitus: theory and practice IV. H. Rifkin and D.J. Porte, editors. Elsevier Science. New York, NY. 299-340. 